\title{
9. Sustainable Aboriginal livelihoods and the Pilbara mining boom
}

\author{
SARAH HOLCOMBE
}

\section{Introduction ${ }^{1}$}

Recently referred to as 'recreational lifestyles' (Johns 2009:22), the various socioeconomic choices that some Aboriginal people make, in remote areas especially, are often contrasted with how these same people should be operating in the 'real economy'. There is considerable debate about the value of the 'real economy' as a term, given that neo-liberalism tends to be the reference point (Altman 2009; Pholi et al. 2009). Nevertheless, if we think in terms of the 'mainstream' - as this term tends to be understood - the mining industry can readily be typified as the 'real' economy. Pilbara Iron, a business arm of Rio Tinto, has had mixed success in engaging Aboriginal people in this economy. Through a range of strategies, however, such as pre-employment programs, 11 per cent of their workforce is now Aboriginal (Rio Tinto 2007:90), though not necessarily all are local native titleholders from the region of the mine. ${ }^{2}$ The focus in this chapter is on the Pilbara Iron Ore operations generally and the activities of Gumala Aboriginal Corporation (Gumala) more specifically.

Gumala was set up in 1998 as one of four structures to manage the Yandicoogina Land Use Agreement (YLUA). As the Aboriginal organisation based at Tom Price, Gumala was developed to act as the voice of the agreement's beneficiaries in developing, researching and preparing proposals for investments and community projects for submission to Gumala Investments Proprietary Limited

\footnotetext{
1 In the earlier stages of drafting this chapter, I was pursuing the path of co-authorship with Don Gordon, who was at that time Gumala Project's Coordinator. He very helpfully provided some up-to-date information about the 'new generation' Gumala and details of research they were undertaking. He left the employ of Gumala in July 2009, however, so the co-authorship plans were necessarily terminated. Along with Gordon, I also acknowledge the discussions held with the then new CEO, Steve Mav. Although one of the aims of this chapter is for it to be of value to Gumala, the views and opinions expressed remain the responsibility of the author.

2 Disaggregating this 11 per cent figure for Aboriginal employment into Aboriginal language affiliation and usual residence would be a very useful exercise.
} 
(GIPL). Apart from managing and maintaining the capital base of the General Foundation, GIPL considers Gumala project-funding requests. Gumala is the sole shareholder of GIPL as trustee, while GIPL has ultimate decision-making power in all matters relating to the foundation. As an independent body, GIPL consists of six members: three non-Aboriginal experts and three Aboriginal beneficiary representatives. The annual meetings are held in Perth. Gumala also operates its own business arm, Gumala Enterprises Proprietary Limited (GEPL). This business arm includes Gumala contracting, ESS Gumala (a hospitality venture) and Gumala tourism, which operates the Karijini Eco-Retreat. Gumala also operates a range of community development programs and business startups, some of which operate through their recently established Member Services Unit. Gumala also has contractual responsibilities to ensure that heritage clearances are undertaken within the area of the YLUA with a unit to expedite such clearances. They now have more than 750 beneficiaries of the agreement, though they began with less than 350 .

In a recent paper (Holcombe 2009), I explored the issue of entrepreneurialism and the possibilities and limitations the YLUA offered for opportunities for individuals. The key question considered was 'how individuals could benefit', especially given the pervasive paradigm of 'community' that structured the agreement's 'community benefit package'. In that paper, I touch on the redevelopment of Gumala as a new-generation organisation that had been restructured and refocused. This was principally as a result of the unsuccessful liquidation attempt of GIPL by Gumala in 2007 and the subsequent 'fallout' from this, which included the loss of senior staff (see Holcombe 2009). That paper also briefly touched on the issue of mine closure, and in this chapter I give further consideration to the post-agreement and post-mine regional economy and the implications this has for Gumala. As noted by Scambary (2007), Gumala 'has become both a focus for the attainment of mainstream economic development in the form of business development and also the attainment of aspirations associated with customary livelihood pursuits' (p. 167, emphasis added).

In 2004-05, Taylor and Scambary (2005) were commissioned by Rio Tinto to profile outcomes of regional participation by Aboriginal people in the Pilbara mining industry. They note that previous research elsewhere in remote Australia had indicated that, despite major agreements,

for a complex set of reasons, Indigenous economic status had changed little in recent decades - dependence on government remains high and the relative economic status of Indigenous peoples residing adjacent to major long-life mines is similar to that of Indigenous people elsewhere in regional and remote Australia. (Taylor and Scambary 2005:1) 
The Taylor and Scambary monograph indicates that this pattern has continued in the Pilbara region. Despite massive mineral development and the signing of significant agreements such as the YLUA, which have been operating for more than 10 years, there is little evidence that the majority of members are better off than their non-member neighbours (Taylor and Scambary 2005:1). In light of these findings, Gumala has a strong interest in developing initiatives that look to ensuring that existing initiatives and any new ones enhance the possibility of their members benefiting from the YLUA. Thus, they have an investment in considering ways to improve services to their beneficiaries. To this end, a recent survey by Gumala - although not directly about employment, but rather about members' housing needs - suggests that Aboriginal employment rates in the Pilbara are significantly higher than Taylor and Scambary (2005) found.

While survey respondents were not asked about their employment directly, they were asked what their main source of income was and what their secondary source was - out of a choice of wages, Centrelink payments, self-employed, sitting fees or heritage surveys, and home duties or none. More than one-third indicated that wages was their main income and about half said Centrelink. Gumala notes (Gordon, Personal communication, 1 June 2009) that as this included people who would not be regarded as being in the workforce (for example, pensioners and mothers caring for young children), it could be that more than half the members who could be regarded as available for work are in fact in the workforce. Gumala notes, however, that this estimate is still tentative as the analysis is not yet completed and respondents were not asked specific questions such as 'Who is your employer?' and 'How long have you been working there?' These questions might be the focus of a future survey.

Although this potentially higher rate of employment is indeed encouraging and suggests that more Gumala members are in mainstream employment than previously recorded, the Gumala organisation notes that it is still significantly less than the general population. An avenue considered in this chapter for developing new employment initiatives is the possibilities that the sustainable livelihoods approach could offer Gumala, and by extension other Aboriginal organisations set up to manage land-use agreements. In Altman's (2009:14) view, the attraction of exploring such alternative approaches to economic development seems 'highly appropriate at this moment in Australia's history, when neoliberal economic rationalism and globalism are under challenge'. 


\section{Situating the sustainable livelihoods approach in wider policy}

I am drawn to exploring the sustainable livelihoods approach, as it offers a suite of systematic engagement tools in an approach that develops social as well as economic sustainability. The sustainable livelihoods approach as used internationally in rural development (Carney 2002; Scoones 1998) has been little applied to development in remote Australia, although this is changing (see Davies et al. 2008; Fisher 2002a). This approach has been central in the international effort of poverty reduction and environmental management in countries throughout Africa, Asia and Latin America, although it has its critics (Brocklesby and Fisher 2003). I will provide some detail about the framework in the next section. Taking a lead from Davies et al. (2008:55), I will consider its potential value in 'illuminating possibilities for new livelihood systems... and local strategies that are adaptive and resilient to the ongoing risks and vulnerabilities faced by desert Aboriginal people and the regions where they live'. The power of this approach to community development lies in its flexibility of application and its people-centred nature, as driven by a responsive and participatory paradigm.

The concept of 'development' is itself, however, a major challenge to policymakers in Australia and has not been engaged with as a policy approach to working with Indigenous Australians (see Holcombe 2006a, 2006b). If one types 'development Australian government' into the Google search engine, the international AusAID program will top the list. The development concept in Australia is only loosely applied to specific programs (which have very little do with development) such as the Community Development Employment Projects (CDEP) program (see Langton 2002). Indeed, Dodson (2009) recently observed that although the Australian Government has received a tick for implementing the Paris Declaration on its international aid effectiveness, the ethos endorsed by this declaration on 'partnerships and participation' is not transferred to Indigenous policy development in Australia.

Rather than delving into the legacy of policy approaches to Aboriginal affairs (see, for instance, Altman and Rowse 2005; Dillon and Westbury 2007; Chapter 1 , this volume), it might be useful to consider instead the potential value of the livelihood approach to shift this ground and unsettle this legacy. Fisher, who introduced the sustainable livelihoods approach to Australia, 'argued that there was little understanding among support agencies of the aspirations of remote Aboriginal people, and very little attention to sustainability when agencies make investment decisions affecting remote communities' (cited in Davies et al. 2008:56). Further, Fisher 'proposed that applying a sustainable livelihoods approach in partnership with remote communities would greatly improve 
understanding of the complex factors that impact on settlement viability, bring greater rigour to investment decisions and promote community members' capacity to express and work towards outcomes they are seeking' (cited in Davies et al. 2008:56).

In light of this, it is useful to reflect on Taylor and Scambary's Pilbara baseline profile, as they observed that:

Policy development involving Indigenous populations has typically been reactive to needs as they become revealed (e.g. in terms of postfacto responses to housing shortages or employment needs), as opposed to being proactive in seeking to anticipate and plan for expected requirements. However, being proactive requires a measure of future requirements for infrastructure, programs and services - a practise that is standard procedure for mainstream regional planning, and not least for the mining industry business units. However, it is something that is rarely achieved, or even attempted for Indigenous communities. (Taylor and Scambary 2005:18)

Similarly, in a recent paper (principally a literature review) on the social dimensions of mining in Australia, Solomon et al. (2008) outline a number of 'research and practise gaps'. One of these is 'community and regional development...such as knowledge of specific regional development such as the impact on the resources boom on other activities in regions, on social cohesion, on infrastructure and the long-term legacy of mining activities and closure' (Solomon et al 2008:146).

As a locally based Aboriginal organisation operating regionally, Gumala is potentially in an ideal position to address these gaps and be reflective of its role in addressing the needs of regional development. Implementing and utilising elements of the livelihoods framework could be a means to do this. Gumala already operates responsively through a participatory paradigm and it has recently developed a member's services unit and a women's advocacy unit. Like any Indigenous organisation, however, it has resource constraints and a constituency that is highly mobile and dispersed, and highly politicised. There are some members of the Gumala constituent beneficiary group (750 plus) who could usefully be re-enfranchised by the collaborative methods the sustainable livelihoods approach advocates. Underlying the value of this approach is the recognition that the agreement offers a range of opportunities that Gumala is becoming increasingly responsive to, in its recognition that for its beneficiaries it is not an either/or situation of 'culture or capitalism'. Before discussing this issue in more detail, however, it seems important to briefly overview the recent regional economic history of the Pilbara to provide some background context. 
As examined elsewhere (Edmunds 1989; Holcombe 2006b), mining tenements in the Pilbara region were taken up by large companies from the 1960s, beginning with Mt Tom Price, and escalating to 11 major open-cut iron-ore mines in the Hamersley Ranges region alone. ${ }^{3}$ Local Aboriginal people were not party to this development and any social development was ceded to economic development as the state government took a back seat to the minerals industry. ${ }^{4}$ In the industry development of closed towns for workers (such as Tom Price), Aboriginal people as non-workers were marginalised. Many had already moved away to the coastto Onslow, Roebourne and Port Hedland-after the 1967 referendum that led to the demand for children's schooling. Work in the pastoral industry had also dried up for a range of reasons, such as the granting of equal pay and increased mechanisation (Brehaut and Vitenbergs 2001). Indeed, although local Aboriginal people had been active in alluvial mining in the region for many years (McLeod 1984; Wilson 1961) or had worked in the pastoral industry, such work readiness was not recognised by the incoming industry, although there were exceptions (Peter Stevens in Olive 1997:81). Likewise, a generation of stockwork expertise was never established, as Aboriginal people were moved off the stations from the late 1960s (Brehaut and Vitenbergs 2001; Olive 1997). This same generation was also the first to systematically receive formalised schooling (see Smith 2002). Today, the Indigenous population of this region thus exhibits many of the traits of the Third World in the First (Young 1995).

\section{The sustainable livelihoods approach}

The sustainable livelihoods approach has only recently gained currency in Australia, although it has been credibly used as a tool in development programs in relation to poverty alleviation internationally since the late 1980s. This approach dates back to the work of Robert Chambers (1987) in the shift away from a technology-centred interventionist approach to a people-centred approach. It incorporates much of what is considered 'best practice' in development when working with marginalised groups. A core strength of the approach is that it focuses on the existing capabilities and strengths of individuals, families and households, rather than their needs and deficits. By analysing these strengthspartly through the framework of an 'asset pentagon' - those that have the potential to reduce poverty are revealed. This pentagon, as a tool, comprises the five forms of capital: human, social, natural, physical and financial (Figure 9.1). This approach understands the conventional economic focus on market

3 These are: Hope Downs, Area C, Yandicoogina (RTIO), BHP Yandi, Channar, Eastern Ranges, Paraburdoo, Tom Price, Marandoo, Brockman and Pannawonica.

4 Interestingly, however, a significant number of Torres Strait Islanders moved to the Pilbara to work establishing mining infrastructure, such as the railway (see the 2006 documentary film Island Fettlers at $<$ http://australianscreen.com.au/titles/island-fettlers/>). 
production, salaried employment and cash income as the key elements of wellbeing as ethnocentric, reductionist and inadequate to account for the ways in which people really make a living (Chambers and Conway 1992). Rather, the approach recognises the often transient, dispersed and diverse nature of such activities when pursued by marginalised people and the importance of reflecting local conditions, priorities and social structures in approaches to development.
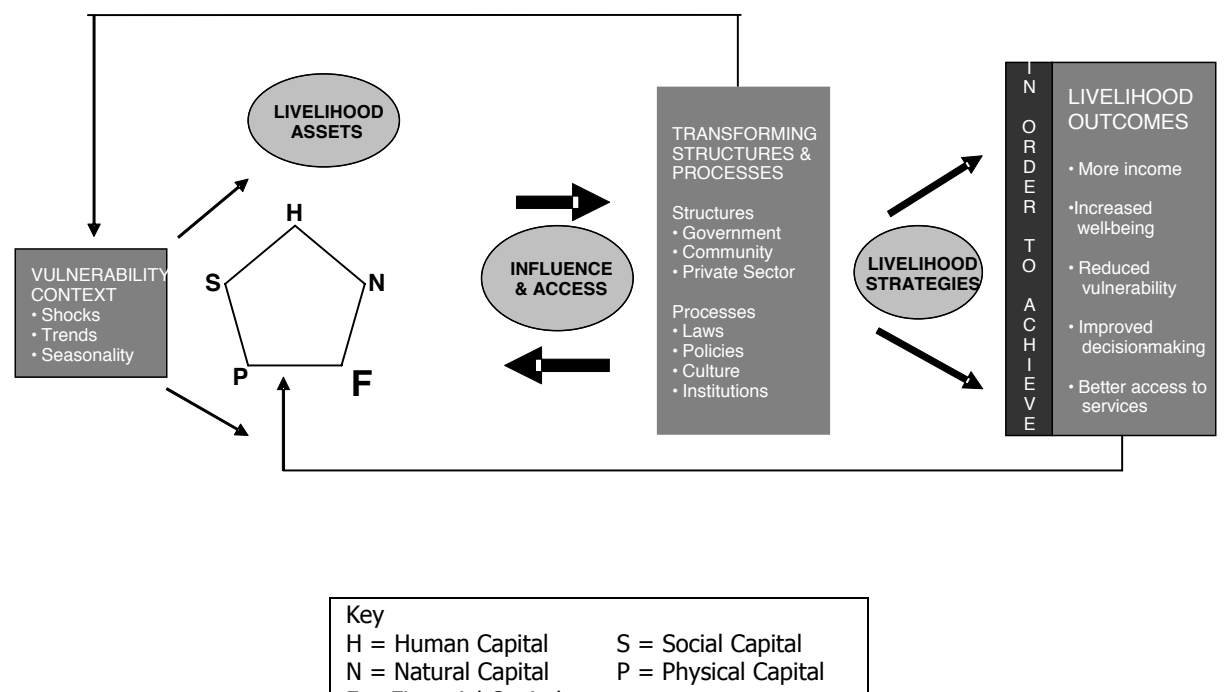

\section{Figure 9.1 Sustainable livelihoods framework}

From Davies et al. (2008:57)

The asset pentagon as a tool could be accused of being over-simplified and too predictable for Aboriginal people, and one could also ask where culture fits in. In remote regions far from market economies, such as most settlements in Central Australia and Arnhem Land, the predominance of assets tends to fall towards social and natural capital, with typical deficits in human, financial and physical capital. Certainly, this was the case in research using this framework in the Central Australian community of Engawala, with participants making the subjective assessment that their natural and social capital stocks were more significant than the other three (Moran et al. 2007:54). In mining-intense regions such as the Pilbara, however, the asset pentagon is likely to take quite a different shape. Without having undertaken field research specifically using this framework in the Pilbara, it seems likely to reveal a far more diverse range of assets, so that such an exercise would reveal more than it elides in the Pilbara region. Nevertheless, I agree with Hinselwood (2003:243) that we should show a 'staunch lack of respect for rigid diagrams' as these can be charged with 
'enticing people into simplicity and rigidity'. If used flexibly, however, the framework, including the asset pentagon, can be an effective tool for organising and analysing ideas.

A brief overview of the preliminary findings from research in the Anmatyerr region (Ti Tree) of Central Australia is useful here, as it could offer some early insight into the potential value of utilising the framework. The research by Measham et al. (cited in Davies et al. 2008) suggested that social capital was the most important asset engaged when local Aboriginal people made decisions about livelihood strategies. The key example of this was that 'many Aboriginal people reported that they began to work in a particular job, or undertook particular activities in the care of land or people, because they were nominated or "picked" by someone else as the person who should do that job' (Davies et al. 2008:60). The implications of this form of job-placement facilitation suggests that a systematic focus on building intra-Aboriginal networks and linkages, as well as focusing on engaging mentors, could be a valuable means of ensuring that available job vacancies are filled.

The sustainable livelihoods framework also promotes a systems perspective by drawing attention to the dynamic nature of people's interactions with government policy and the range of institutions that enable or constrain decisions. It can be understood as a holistic tool in its multi-factoral approach as this attempts to also locate the 'influence' that people have on institutions and the relations of power between them. In this schema, Gumala is understood as an institution that has the power to influence people's assets and strategise outcomes.

As a tool for improving community development practice, the approach was introduced to Australia by Fisher (2002a) through the Centre for Appropriate Technology (CAT) in the Central Australian office in Alice Springs. More recently, it has been taken up by researchers at the Desert Knowledge Cooperative Research Centre (CRC) - notably those working in the Livelihoods in Land project (led by Davies), which aims to 'examine the opportunities for Aboriginal people living in remote locations to manage natural and cultural assets on behalf of Australians and create a livelihood around this activity' (Livelihoods in Land Fact Sheet 89, Core Project 1). ${ }^{5}$

The sustainable livelihood approach, however, is not directly transferable to Australia for a range of reasons outlined by Fisher (2002a). He lists the characteristics that distinguish Australia from the rural communities for which the approach was originally developed in Africa, and so on. The Australian differences include: the remoteness of many communities from main service

5 See the web sites: <http://www.desertknowledgecrc.com.au/research/livelihoods.html $>$ and $<$ http:// www.desertknowledgecrc.com.au/http//www-desertknowledgecrc-com-au/publications/factsheets/DKCRC_ FS.Livelihoods\%20inLand.web.pdf> 
centres and markets; the access of most communities to welfare support or CDEP; the strong connection that Aboriginal people feel to the land; their marginal status within a prosperous liberal economy; and their tradition and culture of hunting and gathering as opposed to sedentary production or enterprise (Fisher 2002b). Likewise, Australia is a 'First World' economy that has allocated the status 'unemployed' to Aboriginal people and they might be marginal to the prosperous liberal economy, but importantly they are a part of it.

Nevertheless, much of the value of the framework lies in its flexibility, its bottomup methodology and the fact that the approach can be used as a research heuristic, as has been done by Davies et al. (2008). The approach is used in their desert research 'as the basis for systems modelling, as a tool for collaborative planning by families and communities, and for improving cross-cultural communication' (Davies et al. 2008:55). The value of the approach for this research chapter lies in its potential to assist the Gumala Aboriginal Corporation to consider a wider range of approaches to delivering benefits to its members. Gumala has an obvious interest in ensuring that its 750-plus beneficiaries under the YLUA do indeed benefit from membership and in exploring new and innovative ways to achieve this. Shifting the focus away from singular outcomes, defined purely by economic drivers, to multiple outcomes that include health and wellbeing, is a value of this approach.

In a previous paper (Holcombe 2009), I utilised the concept of 'community economies' (Gibson-Graham 2002) to give voice to alternative economies that Aboriginal people were attempting to develop-nascent as some of these were. These included bush products, eco and cultural tourism and small-scale pastoralism. Some of these same enterprises are of course still 'on the table' or have been further developed, such as tourism. It seems to me that the sustainable livelihoods approach goes beyond the community economies concept by providing an overarching framework and a language. For instance, the board of CAT adopted a sustainable livelihoods approach for the organisation as a whole. Using the framework as a community planning tool, they see it as a means of understanding the complexities of people's lives by incorporating key elements that have been overlooked by conventional planning, such as the importance of social networks and access to land (Our Place, 3/2002:16). ${ }^{6}$ CAT defines a sustainable livelihood as 'the range of activities that support improved wellbeing through work, enterprise and trading and that can be maintained into the future' (Our Place, 3/2002:16).

An important principle of the sustainable livelihoods approach, according to CAT, is its emphasis on

6 Our Place is the CAT triannual magazine featuring articles produced by CAT about people and technology in remote communities. It is available online at $<$ http://www.icat.org.au/default.asp?action=article $\&$ ID $=3>$ 
the strengths of people, rather than their needs. In particular it aims to achieve an analysis of those strengths which have the potential to reduce poverty. These include the ability of a social group to influence policy, their access to technologies or markets and the resources available to them. (Our Place, 3/2002:16)

Such an approach could work to extend the community-planning repertoire of Gumala to incorporate those beneficiaries who are not employed and who might have remained outside the orbit of engagement with the mining industry or the existing opportunities that Gumala has to offer. Thus, it is not inconsistent with Gumala and the foundation's charter as 'a public benevolent institution for the objects of the relief of poverty, sickness, suffering, distress, misfortune or destitution of the Traditional Owners, particularly those Traditional Owners in the Pilbara Region'. Likewise, this planning approach can operate in tandem with existing successful business-development programs. Working with such an approach is, however, an acknowledgment that a broader set of parameters is required to work effectively, in a long-term way, with a people who have a specific socio-demographic profile at significant variance to the mainstream (Taylor and Scambary 2005) and often very different cultural priorities. As Trigger observes:

Sustainable economic development in Aboriginal communities involves a wide range of matters beyond the essential first steps of making available certain types of jobs, training and business enterprise opportunities. Both the inclinations of individuals to take up such opportunities and, when they do, the subsequent impacts on communities' socio-economic well being, are matters intimately connected to deeply enculturated dispositions and life-practises. (Trigger 2005:51)

\section{‘Deeply enculturated dispositions and life practices'}

In his paper on mining projects in remote Australia, Trigger (2005) both problematises the 'culture concept' and details the implications these different dispositions have for Aboriginal engagement with the mining economy. He is careful not to elide 'culture' as the catch-all concept that is blamed for the lack of uptake of development 'opportunities' or engagement with the mainstream economy. This relationship between Aboriginal culture and economic development has been explored in detail by Peterson (2002) through what he has termed the 'domestic moral economy', building on his earlier work on 'demand sharing' (1993). Peterson notes that as 'with all societies, "sedimented dispositions" among Aboriginal people are only partly articulated 
in any conscious fashion - a point of some relevance to those carrying out "consultations" with regards to planning employment, training and related programs' (in Trigger 2005:51). It seems to me that the sustainable livelihoods approach can also enter here as a tool that attempts to articulate the impacts these different dispositions have on economic engagement through its participatory approach to planning.

It is pertinent here to revisit the four elements that Peterson proposes as constituting the 'domestic moral economy', as these impact on mainstream economic engagement (in Trigger 2005:51, paraphrasing a 2002 conference paper of Peterson's). These are

1. an ethic of generosity informed by a social pragmatics of demand sharing

2. embedded in a system of kin classification that requires a flow of goods and services to produce and reproduce social relationships

3. personhood constituted through relatedness but valuing egalitarian ideology

4. an emphasis on polite indirectness in interaction because open refusal is a rejection of relatedness.

The value, for those in the industry, of learning to recognise and thus acknowledge 'culture' is that it gives voice to Aboriginal economic practices and acts to provide some explanation for behaviours that could appear incomprehensible to non-Aboriginal observers. The need to articulate how the Aboriginal economy operates drove the WA Department of Consumer and Employment Protection and the Department of Community Development to fund a research project on the 'Strategies Goldfields Aboriginal people use to manage in the Aboriginal economy and the mainstream economy at the same time' (Centrecare 2005). This project, entitled 'Living in Two Camps', was underpinned by the 'idea that there were two separate economies that were operating alongside each other at the same time, sometimes reinforcing each other but more often in conflict'. The research found that 'many Aboriginal people, no matter what their material and personal resources, are conscious of how fragile and unpredictable their economic lives can be, and involvement in the Aboriginal economy was a kind of mutual insurance which would guarantee survival if times got tough' (Centrecare 2005:5).

This important point also underscores the value of engaging in multiple economic activities as an effective strategy for survival in highly variable environments, particularly deserts. Indeed, Stafford-Smith (2008) outlines an argument for a 'desert syndrome', which includes managing economically for a stochasticthat is, a highly variable and unpredictable - environment. Although there is increasing evidence that local economies in any region built on a diverse economic base are more resilient in the face of crises, it could be argued that this trait is a tendency that underwrites desert survival. 
On a larger, regional scale, Stafford-Smith (2008:8) notes that the variability and unpredictability of desert economies are driven by distant markets where desert enterprises are usually only a small part of the production system and subject to the vagaries of what is happening elsewhere. Thus, they are price takers, rather than price makers. He further observes that mineral prices are set globally and desert Australia has limited influence over this, and that there have been mining booms before, just as there have been pastoral booms that have, however, left many Aboriginal people unemployed. Thus, a reliance on one form of economy - as a regional economic driver — can be risky in the desert.

Indeed, transferring this logic to a mining economy reminds us that the immensity of regional mining activity has been termed a 'monopsony', whereby industry is virtually the sole buyer of goods and services in their area of operation (Saleem and Behrendt 2001:1). ${ }^{7}$ As the major regional socioeconomic intervention, the scale of the remote mining economy can be demonstrated by Rio Tinto's level of commercial activity alone. In 2001, \$235 million dollars in taxes and royalties were paid to the WA Government and \$1 billion spent in goods and services - the majority in Western Australia (Rio Tinto 2002). This brings us to the question of the sustainability of this mining activity.

\section{Sustainable mining, mine downsizing and mine closure}

The concept of sustainability - as now applied to the triple bottom lines of the social, environmental and economic - is not usually comfortably applied to the extractive-resource industries. As the Pilbara Regional Sustainability Strategy notes, 'it is not possible to sustainably use a non-renewable resource and thus in this sense of the word mining is not sustainable' (Newman et al. 2005:17). Nevertheless, the annual reporting criteria of major corporations, such as Rio Tinto and BHP Billiton, now include the triple bottom line. And interestingly, the Sustainable Development Report for 2007 for Rio Tinto Iron Ore (RTIO) has the 'economic' update as the last section, preceded by sections on governance, social, employees, community and environment. As Newman et al. (2005:18) note in relation to the disjuncture between the sustainability concept and mining, it 'is not whether [mining] can be sustained forever but how can the process the business is using simultaneously improve other social, economic and environmental value[s]'. This is, of course, where a diversity of regional opportunities needs to be considered and where the sustainable livelihoods framework could prove its value.

7 The term 'monopoly' applies to the sole seller of goods and services. 
Planning for mine closure begins in the early stages of project development (Moller et al. 2006:4). In a paper outlining Pilbara Iron's approach to sustainable development in relation to the closure of the Tom Price mine (the oldest of their mines) and Paraburdoo (see Figure 9.2), a set of potential post-closure landuse options was considered as possibly viable. These included such economic activities as 'tourism, environmental and heritage conservation, native title and pastoralism' (Moller et al. 2006:6). No figures, however, were given on when such closure was anticipated or how these alternative economy plans could be realised (and what does 'native title' mean as an economic activity?). This section, however, necessarily touches only on the issue of downsizing or closure and I have not as yet been able to locate specific closure plans for the Rio Tinto Yandi mine.

The Yandi Agreement was originally set to be active for 20 years (1997-2017). With the 'ramp up' or increase in production, this operating period was reduced (as of 2004) to 16 years, and possibly less today. According to this time frame, the YLUA now has only another four years of life. Obvious questions exist around 'what happens to the income stream when the agreement comes to an end? Can it be renegotiated if the mine continues?' And 'what arrangements are there to ensure that the trusts keep generating an income stream?' Such questions direct Gumala to consider whether the organisation and the Aboriginal capacities built to manage it are being built to outlast the agreement.

Compared with gold or zinc mining, for instance, iron-ore mining is long term. This in itself creates a range of issues. When the mining industry is gone from the region in perhaps 20 to 50 years it will doubtless be Aboriginal people who remain, especially given the predominance of 'fly-in/fly-out' workers. Roles for them in rehabilitation seem obvious, utilising the natural resources that remain. Local Aboriginal people would seem to be strategically placed to manage mine-closure issues - as Solomon et al. (2008:147) note: 'the value of a place of capitalist enterprises such as mining is commercial, whereas for Aborigines the value may be both economic and cultural, and for some Aborigines it will be mainly the latter.'

RTIO in the Pilbara operates and maintains a network of 10 mines, three ports and the largest privately owned railway in the world (Milli Milli Magazine 2007). It also manages six pastoral stations in the Pilbara. The cattle barons no longer exist. Though the pastoral leases could be viable, they are essentially valuable to the industry only for the availability of the land they represent. Symbolically and practically, the cattle industry has been marginalised by the mining industry. Not surprisingly, health and safety have apparently 'improved significantly as pastoral employees are now subject to the same requirements as those on the mine site' (Stanton-Hicks 2007:10). 
Environmentally, the footprint of the industry is extremely significant and there clearly has been very significant and, in some cases irreparable, damage to country. For instance, an MA thesis in applied geology on the impacts of mining and mine closure on water quality for the Yandi iron-ore mine notes that there are four possible closure models for the mine pit (Gardiner 2003). Each model has one or two extensive lakes, although none of the scenarios has the lakes with potable water. Indeed, the salinity of the pit lakes would not be expected to stabilise for 1000 years. All models note varying degrees of adverse affects on the downstream creeks. The 2007 RTIO Sustainable Development Report does note, however, that for the Yandi mine, unlike all others in the region, the issue of de-watering is being managed in a more sustainable way. ${ }^{8}$

In the vast areas of 'no-go zones', a number of major access roads require driver awareness training, where the community will be issued a permit and people with a valid driver's licence will be given a driver's awareness card (Milli Milli Magazine 2007). The complex network of roads and the safety requirements of the mine culture have institutionalised and circumscribed people's movements. That some Aboriginal people might feel 'boxed in' by the enormity of the mining footprint is no surprise. The intensity of the environmental footprint and the highly institutionalised mine culture present significant challenges for operating outside it. Perhaps ironically, although the benchmark for gaining work in the industry is extremely high, even given the range of pre-employment programs, the industry is so pervasive that it is difficult to disengage and pursue economic alternatives.

Figure 9.2 goes some way to illustrating the vast areas iron-ore mining incorporates geographically and environmentally; moreover Paraburdoo mine is one of many mines in the region. This picture also shows infrastructure, in the form of roads, which was constructed solely for Pilbara Iron's use.

Skills developed by local Aboriginal people are transferable to other industries and other locations. This assumes, however, that Aboriginal people are migratory and prepared to relocate for work out of their home region. This could be a greater possibility for some, especially in future generations; however, little is known about the extent to which skills acquired by Aboriginal mine workers contribute to the human and social capital of their respective communities (see Barker 2006). Nevertheless, there is little debate that employing local peopleAboriginal and non-Aboriginal - in the mining industry is a more sustainable approach for the region than the current majority approach of fly-in/fly-out (FIFO) (see Armstrong 2004, in Newman et al. 2005). This contentious issue of

8 Ore bodies form a significant aquifer. It is industry and regional practice to discharge water into existing waterways, creating the risk of altering the ephemeral ecosystem. To reduce this risk, Rio Tinto developed a trial aquifer re-injection system, returning the water to the aquifer at an appropriate distance from the mine site (Rio Tinto 2007:59). 
rostering the majority of mining staff as FIFO from large cities such as Perth is a significant sustainability issue indicative of mining revenue leaving the region (see Armstrong 2004, in Newman et al. 2005:40).

Landscape rehabilitation, both during the mine life and post-mine, is an obvious area for Aboriginal employment, if not potentially a livelihood activity. RTIO, however, notes in its 2007 Sustainable Development Report that 'progressive rehabilitation is constrained by the need to maintain ore access and set land aside for future waste dumping sites. Areas are rehabilitated when they are no longer required by operations. Due to rapid expansion in 2007, fewer areas became available for rehabilitation' (Rio Tinto 2007:40). Although it could appear that these significant environmental issues, combined with the regional dominance of the industry, compromise the viability of applying the sustainable livelihoods framework, it seems to me, rather, that it becomes all the more imperative to consider it as a means of economic diversification. Nevertheless, the framework sits most comfortably in remote areas with ample access to natural resources.

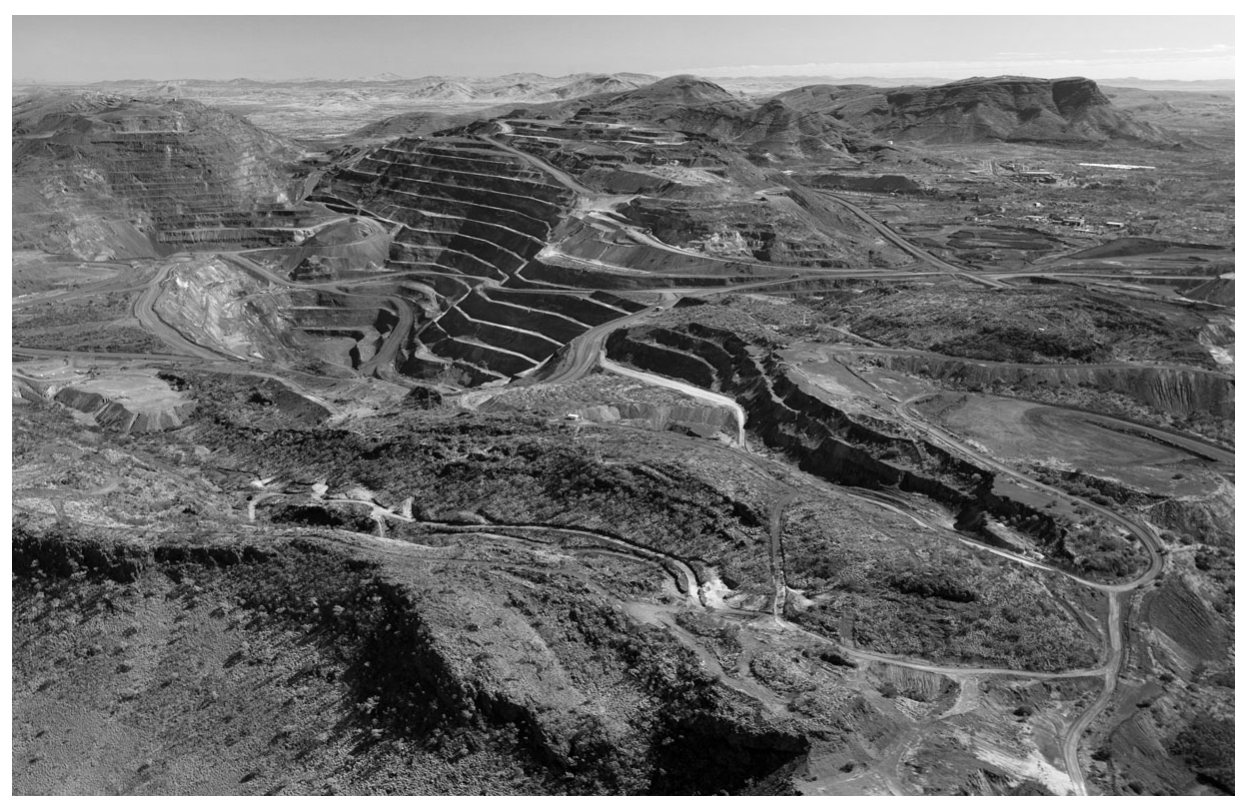

Figure 9.2 Paraburdoo mine looking north-west

Source: Jason Brennan Senior advisor, Communications \& External Relations, Rio Tinto Iron Ore

\section{Homelands}

A strength of the YLUA has been the encouragement for and establishment of outstations or 'homelands', as they are known in the Pilbara. With little state investment in homeland infrastructure, the agreements, notably the YLUA discussed here, have been the drivers of homelands, under the aegis of 
'community development'. According to Gumala, about 120 people (most of whom are Gumala members) live on the three homelands and three 'blocks' that they assist. These three homelands or formal communities are Youngaleena, Wakathuni and Bellary; the three 'blocks' are Wirrilimarra, Windell Block and Ngumee Ngu. Although the majority of Gumala members live in towns in regular houses, Gumala notes that 'the symbolism of homelands is potent' and 'their importance extends well beyond those actually living there' (Gordon, Personal communication, 1 June 2009).

Guerin and Guerin (2008) consider remote communities or homelands as 'spiritual hubs'. They note that although clearly not all people who have rights to live on a homeland are able to, as they might live elsewhere for education or employment, the sustainability of them is dependant on this wider network. Thus, when discussing the sustainability and importance of homelands the issue is not just about how many people live there, but about how wide the influence of all members who live there is (Guerin and Guerin 2008:13). For instance, the homelands in the Pilbara provide a base for important cultural activities, such as annual initiation ceremonies, and a ready departure point for customary economic activity. The value of living on one's country and the more ready access to customary harvest activity have not to my knowledge been explored in this region, as they have in Arnhem Land, for instance (see Altman 1987). Mapping the mobility of Aboriginal residents of towns to homelands to which they have right of access would be a useful exercise in this context. How geographically extensive is the catchment of these homelands?

The Pilbara Regional Sustainability Strategy found that 'the natural environment is a key local advantage of the Pilbara, being the physical basis of resources, tourism, pastoralism and fishing industries, a conservation asset and intimately linked with ongoing Indigenous cultures' (Newman et al. 2005:116). The homelands are clearly at the centre of this resource and thus, in some ways, best placed to capitalise on it.

According to Gumala, in the past decade, it has provided considerable assistance to the six homelands and blocks. It has been the sole developer of the three 'blocks', while it has provided less support than the government for the three homelands. This is, however, set to change, with, according to Gumala, 'the government rethinking its support for homelands and likely to provide less for them' in the future (Gordon, Personal communication, 1 June 2009). At the same time, 'Gumala is conducting a review of its role with the blocks and homelands and this may lead to some increases in support and the establishment of a capital works program' (Gordon, Personal communication, 1 June 2009). 


\section{Heritage clearances as a livelihood strategy}

Perhaps paradoxically, the work that local Aboriginal people, as cultural custodians, undertake for mine expansion and development could be understood in terms of a livelihood approach. This is because it values, or at least purports to value, the existing knowledge and skills that Aboriginal people have in the cultural and environmental values of their land. This work undertaken under the WA Aboriginal Heritage Act (1972) entails groups of Aboriginal people being taken out to areas of proposed mining activity or infrastructure development to ensure that any sites of archaeological and/or spiritual significance are not damaged. Hence, it could be understood as 'harvesting heritage' (see Holcombe 2009).

Acknowledging the pitfalls of this work - such as the politics of ensuring that the right Aboriginal people are invited, and that the gender balance is addressed and that some sites are inevitably sacrificed or compromised-it nonetheless offers some insight into the value of considering this sort of work as a livelihoods strategy. This is because of the possibilities such work affords to regenerating or consolidating the social capital that people have through extended family networks. Indeed, an analysis of how people are chosen for the work could prove telling in light of the work of Measham et al. (cited in Davies et al. 2008) in the Anmatyerr region discussed earlier.

The flexibility the work affords to being out and learning on country can be highly valued, including keeping engaged with the expanding footprint of the mining industry. For instance, in 2004, RTIO 'paid for more than 1000 days of mainly Aboriginal elder time undertaking cultural heritage across the 12 native title groups' (RTIO 2006a:V). This was 'ramped up' in 2006 to 2578 days over 96 surveys (RTIO 2006b:32). Thus, a market value is assigned to this work and it is a routine aspect of Pilbara Iron's (and most other mining companies') work practices.

Nevertheless, it has to be acknowledged that there is a certain tension between the 'ramping up' and hence the need to clear more land, and the knowledge of the land and environment that this work is promoting. One would imagine that the process would become more valuable for the Aboriginal groups involved if there was a standard approach to ensuring that there was opportunity for intergenerational knowledge transmission. That is, to ensuring that younger people always accompanied the 'elders'. It could also be the case, however, that the work is politically volatile for traditional owners. On what basis are people chosen to participate? There are invariably issues around the personalities of the participants - Aboriginal and non-Aboriginal-on both sides. This issue 
of handpicking participants appears, however, to have been managed largely through the development of 'working groups' for each native title claimant group.

It is noteworthy that the RTIO Aboriginal Training and Liaison (ATAL) unit has developed an Archaeological Assistants' Training Course (AATC). ATAL notes that it gives Aboriginal people the opportunity to enhance their skills and knowledge in archaeological theory and practice, including the identification, recording and management of archaeological sites and artefacts. The course was developed following numerous requests from members of the Aboriginal community to gain more training in the field of archaeology. On completion of the AATC, participants receive a Statement of Attainment for partial completion of Certificate II in Metalliferous Mining - Open Cut, with an emphasis on Archaeological Assistant. Certificate II is a nationally recognised qualification under the Australia Quality Training Framework (Pilbara Iron, ATAL 2006).

\section{Conclusion}

This chapter has been a speculative consideration of the sustainable livelihoods strategy as a framework and language for Gumala, and potentially other Aboriginal organisations set up to manage agreement flows. Considering the sustainable livelihoods approach in the context of a regional mining boom recognises that not all Aboriginal people are either able or willing to seek employment in the industry. Employment parity between Aboriginal and nonAboriginal people might never be reached or, indeed, if we assume that it can, it could take several generations. This also assumes, however, that assimilation is inevitable and that the mine economy is somehow infinite or ongoing, which of course it is not. What does appear to be ongoing is Aboriginal people's attachment to homelands and the country on which they are situated.

So it seems that the Pilbara region at least, with its access to a mine economy, has a relative advantage in the support that Aboriginal native titleholders receive for homeland or outstation development. Likewise, the leverage that Gumala is able to gain from the state and commonwealth governments from already having a certain baseline of funding is also crucial for their continuing support. There is also evidence, albeit from Gumala, that there are more Aboriginal people employed in the mining industry than was found by Taylor and Scambary (2005). The extensive pre-employment programs that Rio Tinto and others such as Ngarda Civil and Mining have implemented appear to be making their mark.

The possibilities for sustainable livelihoods are clearly compromised by the pervasiveness of mining in the Pilbara region and the footprint of the industry, as this encompasses not only the actual mines, but also the complex network 
of infrastructure, water requirements, and so on. Likewise, mining cannot sit comfortably with the concept of sustainability, unless there is directed focus on developing the region's other capital - the social, cultural, human and environmental. As Armstrong (in Newman et al. 2005:40) argues, 'a sustainable solution to FIFO in the Pilbara is about increasing the positive benefits of mining to local communities whilst reducing their dependence upon it'. Gumala is in a strategic position in the region to do this and deliver sustainable outcomes.

Trigger (2005:54) notes that 'the research literature squarely suggests that a form of fundamental cultural change is implicated in economic development-based solutions to Indigenous disadvantage. To frame this positively, new ways must be found of articulating market participation with a number of key Indigenous values.' In engaging with the sustainable livelihoods approach and engaging with Gumala - as an Aboriginal organisation set up to harness benefits from the YLUA - this chapter has gone part of the way to finding such alternative forms of articulation. Likewise, whether we use the language of 'sustainable livelihoods' or 'community economies' is not necessarily the point. Rather, the point of this chapter has been to articulate the value of alternative frameworks for economic engagement from the mainstream against the backdrop of mine downsizing or mine closure, the broader issues of sustainability and the 'deeply enculturated dispositions' of Aboriginal people. Nevertheless, the consideration of mine closure issues has been preliminary only and international comparative research could usefully be undertaken, specifically on the Brazilian iron-ore mining industry - one of the largest competitors with the Pilbara.

\section{Bibliography}

Ah Mat, R. 2003, The moral case for Indigenous capitalism, Address to the NTRB Native Title on the Ground Conference, Alice Springs, NT, 5 June 2003, <http://ntru.aiatsis.gov.au/conf2003/papers/ahmat.pdf>

Altman, J. C. 1987, Hunter-Gatherers Today: An Aboriginal economy in north Australia, Australian Institute of Aboriginal Studies, Canberra.

Altman, J. C. 2009, Beyond closing the gap: valuing diversity in Indigenous Australia, CAEPR Working Paper No. 54/2009, Centre for Aboriginal Economic Policy Research, The Australian National University, Canberra.

Altman, J. C. and Rowse, T. 2005, 'Indigenous affairs', in P. Saunders and J. Walter (eds), Ideas and Influence: Social science and public policy in Australia, UNSW Press, Sydney, pp. 159-77. 
Indigenous Participation in Australian Economies

Barker, T. 2006, Employment outcomes for Aboriginal people: an exploration of experiences and challenges in the Australian minerals industry, Research Paper No. 6, Centre for Social Responsibility in Mining, University of Queensland, St Lucia, <http://www.csrm.uq.edu.au/docs/t06.pdf>

Brehaut, L. and Vitenbergs, A. (eds) 2001, The Guruma Story. Told by Guruma Leaders Group, led by Peter Stevens, IAD Press, Alice Springs, NT.

Brocklesby, M. A. and Fisher, E. 2003, 'Community development in sustainable livelihoods approaches - an introduction', Community Development Journal, vol. 38 (3 July), pp. 185-98.

Carney, D. 2002, Sustainable Livelihoods Approaches: Progress and possibilities for change, Department for International Development, United Kingdom.

Centrecare [Sercombe, H.] 2005, Living in two camps: the strategies Goldfields Aboriginal people use to manage in the Aboriginal economy and the mainstream economy at the same time, Unpublished report of a research project funded by the Department for Consumer and Employment Protection and the Department for Community Development, Government of Western Australia.

Chambers, R. 1987, Sustainable livelihoods, environment and development: putting poor rural people first, Institute of Development Studies Discussion Paper 240, University of Sussex, UK.

Chambers, R. and Conway, G. 1992, Sustainable rural livelihoods: practical concepts for the 21st century, Institute of Development Studies Discussion Paper 296, University of Sussex, UK.

Davies, J., White, J., Wright, A., Maru, Y. and LaFlamme, M. 2008, 'Applying the sustainable livelihoods approach in Australian desert Aboriginal development', The Rangeland Journal, Special Issue: Desert knowledge, vol. 30, no. 1, pp. 55-65.

Dillon, M. and Westbury, N. 2007, Beyond Humbug: Transforming government engagement with Indigenous Australia, Seaview Press, South Australia.

Dodson, M. 2009, Communities in control: the real Australian experience, 2009 Community Leadership Oration, Communities in Control Conference, Moonee Valley Race Club, Vic., June 2009.

Edmunds, M. 1989, They Get Heaps: A study of attitudes in Roebourne Western Australia, Aboriginal Studies Press, Canberra.

Fisher, S. 2002a, 'The sustainable livelihoods approach: a path well travelled', Our Place, vol. 3, no. 19, pp. 16-17. 
Fisher, S. 2002b, A livelihood less ordinary: applying the sustainable livelihoods approach in the Australian Indigenous context, Centre for Appropriate Technology Paper, viewed 23 February 2009, <http://www.icat.org.au/ media/Research/work \%20and \%20livelihoods/Livelihood-less-ordinary. $\mathrm{pdf}>$

Gardiner, S. J. 2003, Impacts of mining and mine closure on water quality and the nature of the shallow aquifer, Yandi iron ore mine, Unpublished Master of Science thesis, Department of Applied Geology, Curtin University of Technology, WA, viewed 22 May 2009, <http://espace.library.curtin.edu. au:1802/view/action/nmets. do?DOCCHOICE $=15728 . x m l \& d v s=1245809919$ 322 $725 \&$ locale $=$ en_US \&search_terms $=000012589 \&$ usePid $l=$ true $\&$ usePid $2=$ true $>$

Gibson-Graham, J. K. 2002, 'Beyond global vs. local: economic politics outside the binary frame', in A. Herod and M. Wrights (eds), Geographies of Power: Placing scale, Blackwell Publishers, Oxford, pp. 25-60.

Guerin, B and Guerin, P. 2008, Mobility and sustainability of remote Australian communities: community issues, Desert Knowledge Symposium and Showcase, Alice Springs, NT, 3-6 November.

Hinselwood, E. 2003, 'Making friends with the sustainable livelihoods framework', Community Development Journal, vol. 38 (3 July), pp. 243-54.

Holcombe, S. 2005, 'Indigenous organisations and miners in the Pilbara, Western Australia: lessons from a historical perspective', Aboriginal History, vol. 29, pp. 107-35.

Holcombe, S. 2006a, The challenge of sustainability in remote settlements, Paper presented at the Desert Knowledge CRC Symposium, Alice Springs, NT, November, <http://www.desertknowledgecrc.com.au/socialscience/ downloads/DKsymposiumabpapFRD.pdf $>$

Holcombe, S. 2006b, 'Community benefit packages: development's encounter with pluralism in the case of the mining industry', in T. Lea, E. Kowal and G. Cowlishaw (eds), Moving Anthropology: Critical Indigenous studies, Charles Darwin University Press, Darwin, pp. 79-94.

Holcombe, S. 2009, 'Indigenous entrepreneurialism in the context of mining land use agreements', in J. C. Altman and D. F. Martin (eds), Power, culture, economy: Indigenous Australians and mining, CAEPR Monograph 30, ANU E Press, Canberra, pp. 149-69. 
Johns, G. 2009, No Job No House: An economically strategic approach to remote Aboriginal housing, The Menzies Research Centre Ltd, Canberra, <http:// www.mrcltd.org.au/research/indigenous-reports/No_Job_No_House.pdf >

Langton, M. 2002, A new deal? Indigenous development and the politics of recovery, Dr Charles Perkins AO Memorial Oration delivered at the University of Sydney, Sydney, October 2002, <http://ses.library.usyd.edu. au/bitstream/2123/1634/1/Langton \% 20Perkins\%20Oration \%20USyd \% 20 Oct $\% 202002$.pdf $>$

Levitus, R. 1999, 'Local organisations and the purpose of money', in J. C. Altman, F. Morphy and T. Rowse (eds), Land rights at risk? Evaluations of the Reeves Report, Research Monograph No. 14, Centre for Aboriginal Economic Policy Research, The Australian National University, Canberra.

Levitus, R. with Altman, J. C. 1999, The allocation and management of royalties under the Aboriginal Land Rights (Northern Territory) Act: options for reform, CAEPR Discussion Paper No. 191, Centre for Aboriginal Economic Policy Research, The Australian National University, Canberra.

McLeod, D. 1984, How the West was Lost: The native question in the development of Western Australia, D. W. McLeod, Port Hedland, WA.

Milli Milli Magazine 2007, 'Rio Tinto iron ore', Milli Milli Magazine, 27 July 2007, <http://www.riotintoironore.com/documents/Milli_Milli_27.pdf>

Moller, M., Flugge, R. and Murphy, D. 2006, Pilbara Iron's approach to sustainable development during mine closure - the case study of greater Tom Price and Pannawonica operations, Unpublished report, Sinclair Knight Merz, Australia.

Moran, M., Wright, A., Renehan, P., Szava, A., Beard, N. and Rich, E. 2007, The transformation of assets for sustainable livelihoods in a remote Aboriginal settlement, Desert Knowledge CRC Report 28, Desert Knowledge CRC, Alice Springs, NT.

Newman, P., Armstrong, R. and McGrath, N. 2005, Pilbara Regional Sustainability Strategy: A discussion document, Institute for Sustainability and Technology Policy, Murdoch University, Perth.

Olive, N. (ed.) 1997, Karijini Mirlimirli: Aboriginal histories from the Pilbara, Fremantle Arts Centre Press, Perth.

Peterson, N. 1993, 'Demand sharing: reciprocity and pressure for generosity among foragers', American Anthropologist, vol. 95, no. 4, pp. 860-74. 
Peterson, N. 2002, From mode of production to moral economy: sharing and kinship in fourth world social orders, Paper presented to the Ninth International Conference on Hunting and Gathering Societies, Edinburgh, Scotland, 9-13 September.

Pholi, K., Black, D. and Richards, C. 2009, 'Is "Close the Gap" a useful approach to improving the health and wellbeing of Indigenous Australians?', Australian Review of Public Affairs, vol. 9, no. 2, pp. 1-3.

Pilbara Iron, ATAL 2006, Working with us: Aboriginal Training and Liaison (ATAL), web content, <http://www.pilbarairon.com/SiteContent/working/ atal.asp $>$

Rio Tinto 2002, Future Matters Newsletter, Winter 2002, Rio Tinto, Perth.

Rio Tinto 2007, Annual Report 2007, Rio Tinto, Perth.

Rio Tinto Iron Ore (RTIO) 2006a, Breaking New Ground: Stories of mining and the Aboriginal people of the Pilbara, Quality Press, WA.

Rio Tinto Iron Ore (RTIO) 2006b, Pilbara Operations Sustainable Development Summary Report: More value with less impact, viewed 3 July 2008, <http:// www.pilbarairon.com.au/sd/RTIO \%20Sust \%20Dev\%20Summary\%20(FA). pdf>

Saleem, A. and Behrendt, L. 2001, 'Mining and Indigenous rights: the emergence of a global social movement', Cultural Survival Quarterly, vol. 25, no. 1, p. 5.

Scambary, B. 2007, My country, mine country: Indigenous people, mining and development contestation in remote Australia, Unpublished $\mathrm{PhD}$ dissertation, The Australian National University, Canberra.

Scoones, I. 1998, Sustainable rural livelihoods: a framework for analysis, Institute of Development Studies Working Paper 72, Institute of Development Studies, Brighton, UK, <http://www.uvg.edu.gt/instituto/centros/cea/Scoones72. pdf>

Smith, A. B. with Vitenbergs, A. and Brehaut, L. 2002, Under a Bilari Tree I Born, Fremantle Arts Centre Press, Perth.

Solomon, F., Katz, E. and Lovel, R. 2008, 'Social dimensions of mining: research, policy and practice challenges for the minerals industry in Australia', Resources Policy, vol. 33, pp. 142-9.

Stafford-Smith, M. 2008, "The "desert syndrome" — causally linked factors that characterise desert Australia', The Rangeland Journal, vol. 30, pp. 3-14. 
Stanton-Hicks, E. 2007, Sustainability and the iron ore industry in the Pilbara: a regional perspective, Masters thesis, Institute for Sustainability and Technology, Murdoch University, Perth, <http://www.sustainability.dpc. wa.gov.au/CaseStudies/pilbara/pilbaraprint.htm $>$

Taylor, J. and Scambary, B. 2005, Indigenous people and the Pilbara mining boom: a baseline for regional participation, CAEPR Research Monograph No. 25, ANU E Press, Canberra.

Trigger, D. 2005, 'Mining projects in remote Australia: sites for the articulation and contesting of economic and cultural futures', in D. Austin-Broos and G. MacDonald (eds), Culture, Economy and Governance in Aboriginal Australia. Proceedings of a Workshop held at the University of Sydney, 30 November - 1 December, 2004, Sydney University Press, NSW.

Wilson, J. 1961, Authority and leadership in a 'new style' Australian Aboriginal community: Pindan Western Australia, Unpublished MA thesis, University of Western Australia, Perth.

Wilson, J. 1980, 'The Pilbara Aboriginal social movement: an outline of its background and significance', in R. Berndt and C. Berndt (eds), Aborigines of the West: Their past and their present, University of Western Australia Press, Perth.

Young, E. 1995, Third World in the First: development and indigenous peoples. Routledge, London. 